\title{
(1⿶)
}

Citation:

Stafford, A and Johnston, D and Miles-Shenton, D and Farmer, D and Brooke-Peat, M and Gorse, C (2014) Adding value and meaning to coheating tests. Structural Survey, 32 (4). 331 - 342 . ISSN 0263-080X DOI: https://doi.org/10.1108/SS-01-2014-0007

Link to Leeds Beckett Repository record:

https://eprints.leedsbeckett.ac.uk/id/eprint/221/

Document Version:

Article (Accepted Version)

The aim of the Leeds Beckett Repository is to provide open access to our research, as required by funder policies and permitted by publishers and copyright law.

The Leeds Beckett repository holds a wide range of publications, each of which has been checked for copyright and the relevant embargo period has been applied by the Research Services team.

We operate on a standard take-down policy. If you are the author or publisher of an output and you would like it removed from the repository, please contact us and we will investigate on a case-by-case basis.

Each thesis in the repository has been cleared where necessary by the author for third party copyright. If you would like a thesis to be removed from the repository or believe there is an issue with copyright, please contact us on openaccess@leedsbeckett.ac.uk and we will investigate on a case-by-case basis. 


\section{Adding Value and Meaning to Coheating Tests}

Anne Stafford, David Johnston, Dominic Miles-Shenton, David Farmer, Matthew Brooke-Peat and Chris Gorse Centre for the Built Environment (CeBE), Leeds Metropolitan University, Leeds, UK

\section{Structured Abstract:}

Purpose: The coheating test is the standard method of measuring the heat loss coefficient of a building, but to be useful the test requires careful and thoughtful execution. Testing should take place in the context of additional investigations in order to achieve a good understanding of the building and a qualitative and (if possible) quantitative understanding of the reasons for any performance shortfall.

Design/Methodology/Approach: The authors have access to more than twenty years of experience in coheating testing. This experience is drawn upon to discuss practical factors which can affect the outcome, together with supporting tests and investigations which are often necessary in order to fully understand the results.

Findings: If testing is approached using co-heating as part of a suite of investigations, a much deeper understanding of the test building results. In some cases it is possible to identify and quantify the contributions of different factors which result in an overall performance shortfall.

Practical implications: Although it is not practicable use a fully investigative approach for large-scale routine quality assurance, it is extremely useful for purposes such as validating other testing procedures, in-depth study of prototypes or detailed investigations where problems are known to exist.

Social implications: Successful building performance testing is a vital tool to achieve energy saving targets.

Originality/Value: The approach discussed clarifies some of the technical pitfalls which may be encountered in the execution of coheating tests and points to ways in which the maximum value can be extracted from the test period, leading to a meaningful analysis of the building's overall thermal performance.

Keywords: Coheating test; thermal performance; building fabric; heat loss coefficient 


\section{Introduction}

In the UK there is a growing recognition that a discrepancy between the expected and measured thermal performance of buildings is common. To some extent this is unsurprising, since expected performance is calculated at present without applying tolerances to the design, the materials used or the real building processes (Zero Carbon Hub, 2010). However, the size of the discrepancy (or "performance gap" as it is often called) is extremely variable, and can in some cases be as large as $100 \%$ or more. Although the body of evidence for the performance gap is still small, it is persuasive and growing all the time, and applies to both new-build and refurbishment activities (Stafford et al., 2012). Unless this issue is addressed as a matter of urgency, it has the potential to prevent projected carbon-savings from both new-build and refurbishment activities from being achieved in practice.

The necessary quality control could be put in place via a requirement for routine testing, to measure the thermal performance of a significant sample of buildings. However, this is neither simple nor straightforward. The standard method used at present for measuring overall fabric thermal performance is the coheating test, which results in a single heat loss coefficient (HLC) value, representing the actual rate of heat energy loss per degree difference between internal and external temperature, under the test conditions. While this metric can be useful for comparison purposes, or for assessing the success (or otherwise) of refurbishment projects, it is often only part of the story. What is more, the nature of the coheating test itself tends to make it unsuitable for large-scale, routine use.

\subsection{Important Complicating Factors and Requirements for Coheating Testing}

The coheating test is generally regarded as the most robust method for establishing a steady-state whole-building heat loss coefficient (HLC) value. The test has been developed over a number of years from its initial form in the late 1970s (Sonderegger et al., 1979; Sonderegger and Modera, 1979) to its present form as described by Johnston et al. (2013). Essentially the method depends upon maintaining an even, elevated internal temperature throughout the test building, and tracking the power input required to achieve this, together with the variations in external temperature which give rise to an internal/external temperature difference. However, a number of factors impact upon the successful execution of the test.

a. Solar

The electrical power input to the test building is easily measured. However, there is likely to be solar input also, which is less easily accounted for. The usual procedure is to minimise solar effects by ensuring that tests are undertaken during the winter months (usually October - March in the UK), when there is less direct insolation. Nevertheless, it is still a factor which usually has to be accounted for, either by estimation or by incorporating insolation measurements into the statistical analysis. In some cases where external weather conditions are unfavourable, neither method may be entirely satisfactory, and this can give rise to variation between $\mathrm{HLC}$ measurements on the same building under different environmental conditions. 


\section{b. Other Environmental Factors}

Wind may also impact upon the results of a test if not fully accounted for in the analysis. The detailed effects of wind are not well understood, but it is known that in some cases the wind direction can be important as well as the speed and the impact of any gusting, making analysis somewhat difficult. Similarly, moisture can have an effect on the heat loss characteristics of the building fabric.

c. Temperature Measurement

The test relies on maintaining a constant internal temperature throughout the building. Achieving this may require the deployment of a large number of heaters and/or distribution fans, together with some experience. The careful deployment of fans assists in achieving and maintaining an even temperature throughout the whole building. An internal/external temperature difference of at least $10^{\circ} \mathrm{C}$ is recommended, which again suggests that the test should be confined to the colder months of the year. Furthermore, variability in the temperature differential is crucial in order to obtain a good spread of data points. Care is also needed to ensure that high mean elevated internal temperatures are avoided, otherwise there is a risk that damage could occur to the fabric due to thermal stress. Also, the thermal conductivity of building elements may be affected by unusually high temperatures. A maximum internal temperature of $25^{\circ} \mathrm{C}$ is usually recommended.

\section{d. Time, Expertise and Cost}

In order to collect sufficient high-quality data, a measurement period of at least two weeks is usually required. This may be extended considerably if conditions are unfavourable. During the measurement period the building must remain unoccupied. Therefore the test can be costly and time-consuming.

Clearly the environmental factors (solar, wind, moisture etc.) prevalent during the test mean that there is a degree of inherent error or variability in the final HLC value obtained. It is not yet understood exactly how this error should be characterised, but it is known that good repeatability can be obtained by experienced researchers following a principle of ensuring the test is not excessively affected by solar gain or unusual wind conditions.

\section{Using the Coheating Test as a Research Platform}

It should be clear from the above discussion that performing a high-quality coheating test requires a time investment of several weeks. Experience and a good understanding of the building itself and the environmental conditions prevalent during the test period will allow the researchers to optimise and understand the HLC result obtained. This should be seen as an opportunity, rather than simply as a limitation of the test.

The coheating test as normally performed by the Centre for the Built Environment (CeBE) at Leeds Metropolitan University, incorporates a wide range of additional tests and investigations. These additional investigations lead to a much greater understanding of the building than could be gained from an attempt to measure HLC in a routine or simple procedural fashion, and in many 
circumstances can result in a quantitative understanding of the differences between measured and designed heat loss (especially in the case of new-build where it has been possible to observe construction procedures also).

The following sections summarise some brief examples of other tests and investigations which are often undertaken during the coheating test period, together with examples of some lessons learned during real tests. These additional tests and investigations add further context to the coheating test result, and help to explain the reasons for any discrepancies between expected and measured heat loss coefficients. They should not be regarded as alternatives, but instead represent a set of tools, any or all of which may be needed to build up a full understanding in a particular building.

In some cases the sources and locations of examples have not been revealed in order to comply with issues of confidentiality and commercial sensitivity.

\section{1: Thermography and Smoke Testing}

There are a number of opportunities for the use of thermography to enhance understanding of the building, both during the heat-up/cool-down phases and also when the building has reached a steady elevated temperature. Thermography can be conveniently combined with smoke testing during the pressurisation tests (ATTMA, 2010) which are normally performed the beginning and at the end of the coheating phase. Thermography (often under depressurisation) and smoke-testing (usually under pressurisation) can both help to identify leakage paths. A whole raft of issues are commonly observed by the authors, including poor sealing of penetrations, poorly fitting windows and doors, problems around floors, air movement behind plaster-boarding, leakage around loft hatches and so on.

The following figures show examples of issues identified by thermography (figs 1 and 2) or by a combination of thermography and smoke testing (figs 3 and 4). Fig. 2 is taken from the report 'Understanding the gap between designed and real performance: Lessons from Stamford Brook' (Wingfield et al., 2011b).

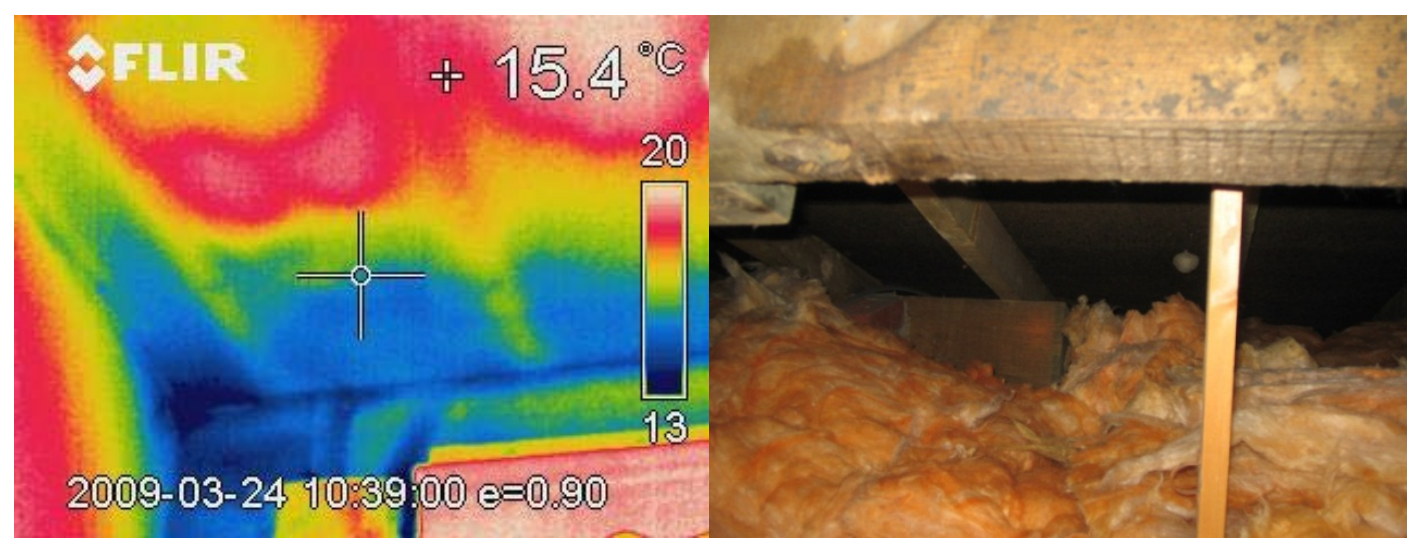

Figure 1: Cooler areas near ceiling edge found to be a result of missing loft insulation behind purlin in eaves area. 

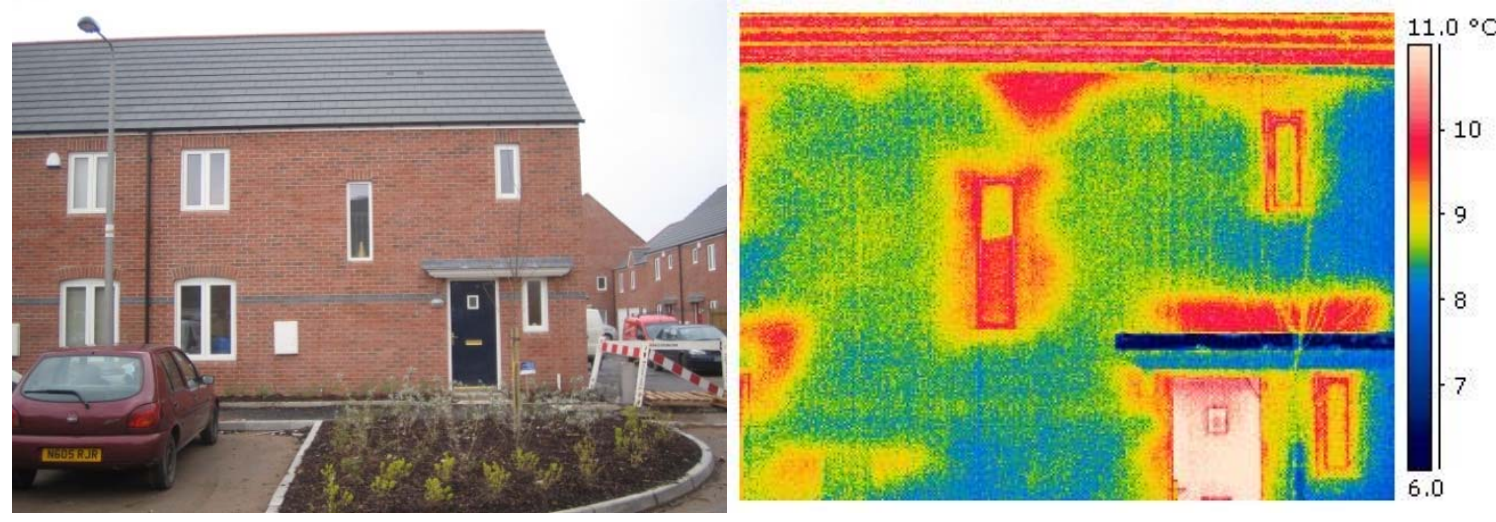

Figure 2: Example of missing, slumped or incomplete cavity wall insulation. Taken from the report 'Understanding the gap between designed and real performance: Lessons from Stamford Brook' (Wingfield et al., 2011b)
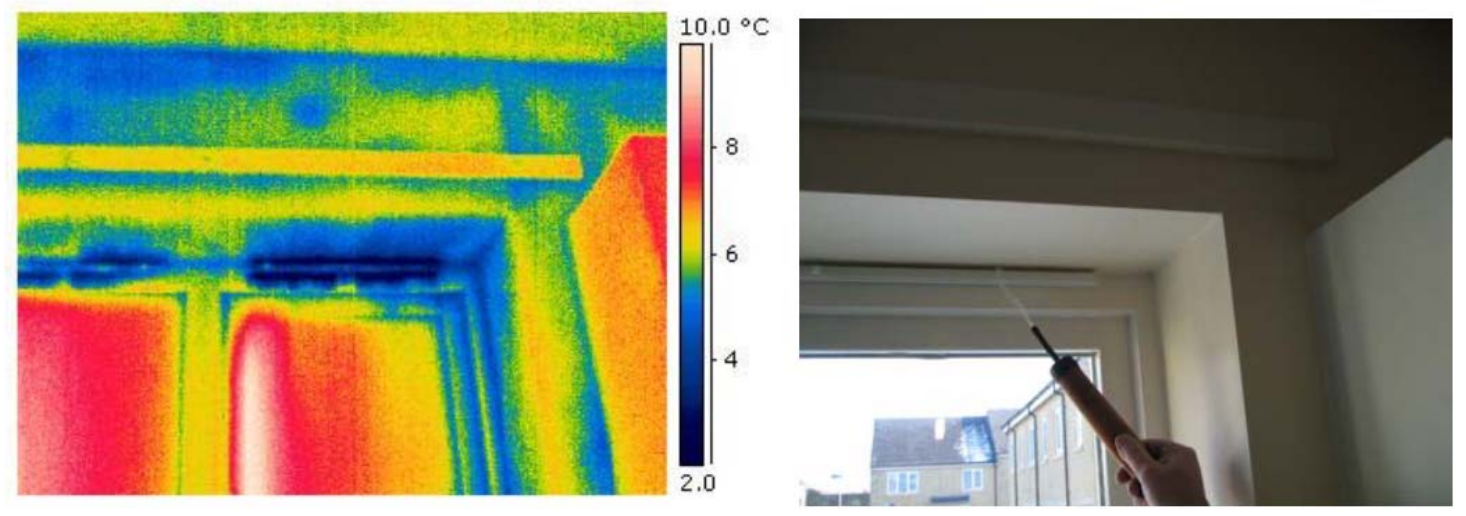

Figure 3: Air leakage through and around poorly fitting and/or poorly closing window trickle vents.

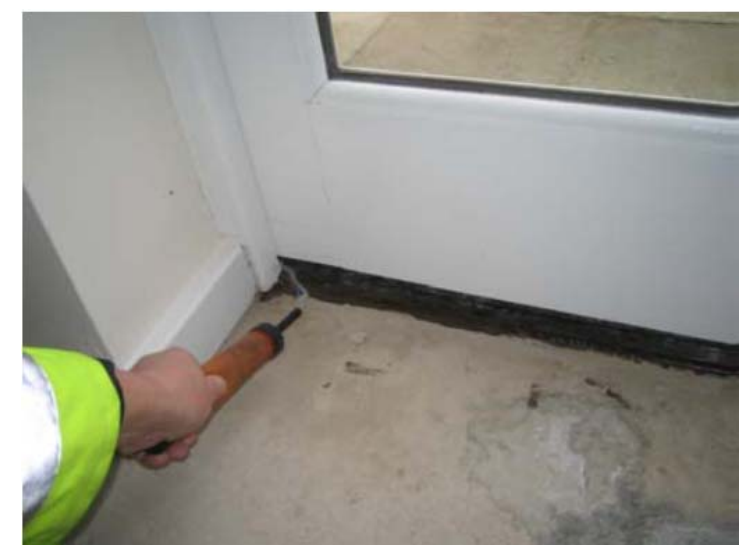

Figure 4: Air leakage under patio doors.

Repeated thermal imaging throughout the heat-up phase can also help to distinguish between thermal lag/inertia, surface effects and bulk effects.

\section{2: Heat Flux Measurements.}

The co-heating test conditions are ideal for simultaneously measuring the in situ U-values of plane elements using heat flux sensors, since the elevated temperature ensures that heat is transferred 
largely uni-directionally, from the internal to the external environment. Internal and external temperatures will already be controlled or monitored as part of the co-heating test. Indeed, ISO 9869:1994 (ISO, 1994) specifically states that a stable elevated internal temperature during the heat flux measurement period increases the accuracy of an in situ U-value estimate. Standard practice at Leeds Metropolitan University is to investigate any element of interest using an array of several heat flux sensors, so that variations of positioning or element structure can be captured.

Thermal imaging can identify potential areas of interest so that heat flux sensors can be placed appropriately to quantify differences in in situ U-value. For example, the thermal image in Figure 5 below suggested the presence of air movement behind the internal plasterboard which was subsequently investigated further using a vertical array of heat flux sensors to give a better estimate of the overall in situ wall U-value.

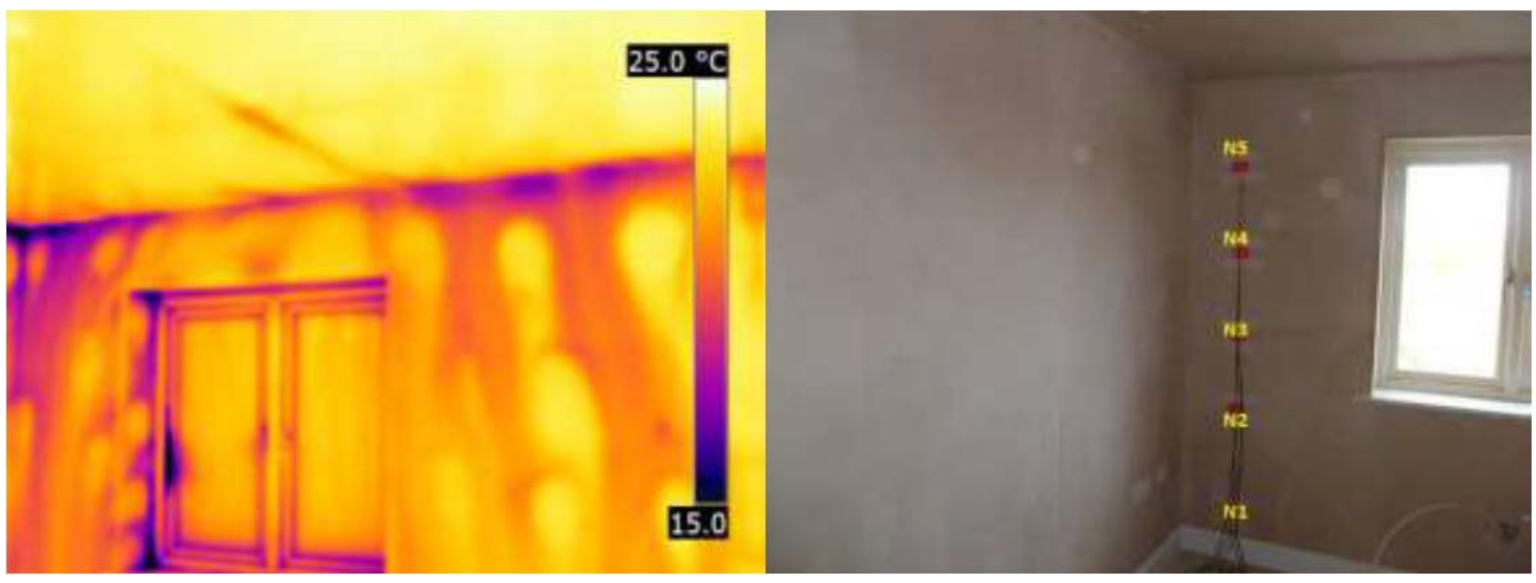

Figure 5: Thermal image influencing placement of heat flux sensors. Images supplied by D. Farmer (private communication).

In a similar way, heat flux measurements have also been used in this context to identify and estimate the effects of thermal bypasses, for example the bypass associated with unfilled cavity party walls, which was formally recognised in the 2010 UK Building Regulations, following work done by Bell and Wingfield at Leeds Metropolitan University. The mechanism was first posited following work done at Stamford Brook (Lowe et al., 2007), but the example shown in fig 8 below is taken from the Technical Note on Measurement of Heat Loss via Thermal Bypasses in Separating Party Wall Cavities (Wingfield, 2010) 


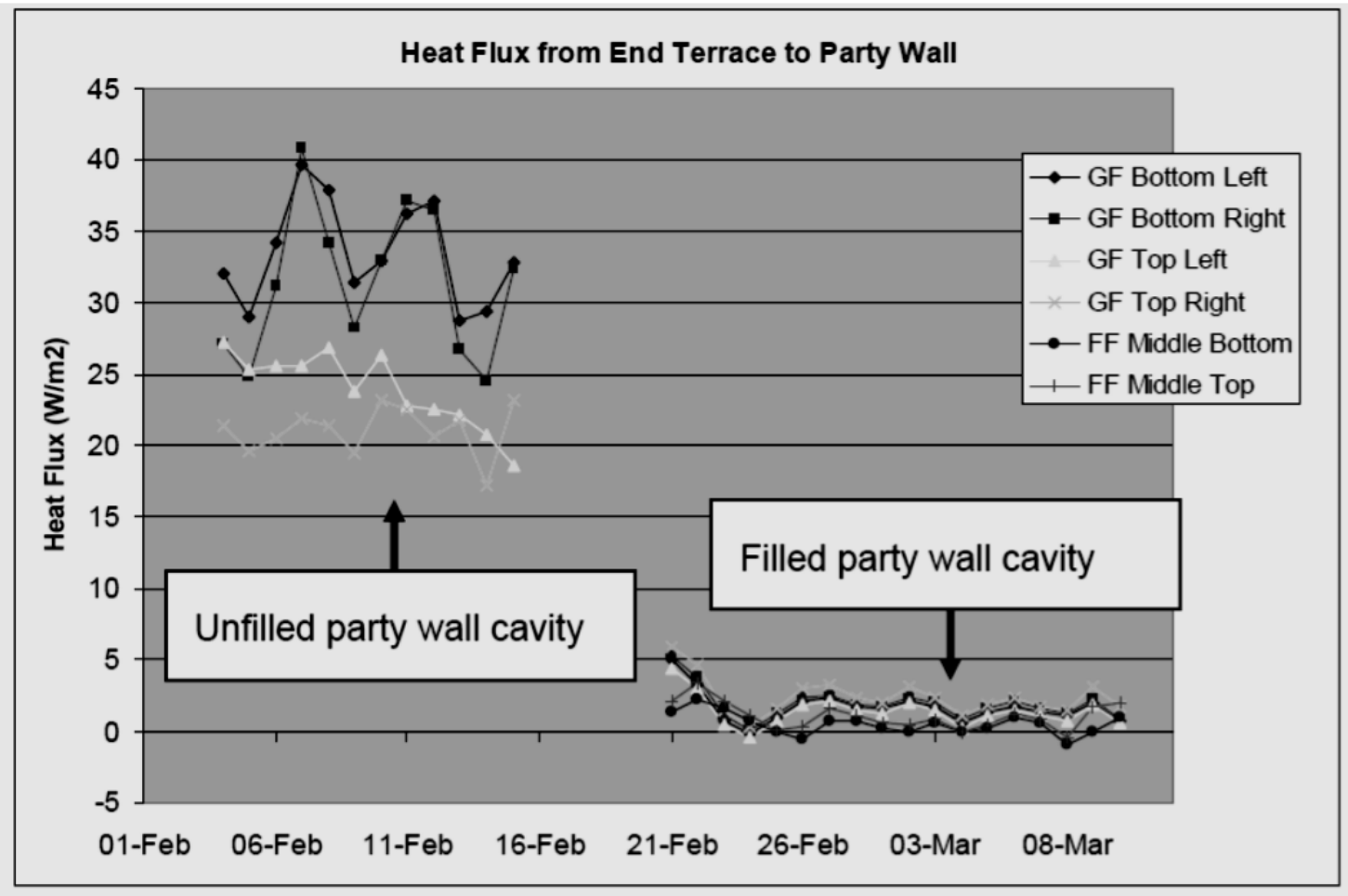

Figure 8: Heat flux data before and after fully filling and edge sealing of a party wall cavity. Taken from Wingfield (2010).

Other forensic methods can also be used to characterise party wall and other bypasses, including (but not limited to):

- $\quad$ Cavity temperature measurements

- Surface temperature measurements

- Air velocity and air flow direction measurements in cavities

- Pressure differential measurements

- Thermal imaging.

- Smoke injection.

\section{3: Thermal Modelling}

In some cases as-built junctions do not match the design specifications. Furthermore, the thermal performance of junctions does not improve in proportion to the increase in performance of plane elements when insulation is added, e.g. in refurbishment projects. Therefore modelling of junctions can be useful in identifying higher than expected thermal bridging heat losses, or even potential condensation risks. Such risks can also occur in attached properties where thermal upgrading works are undertaken in a neighbouring building because the fabric at the junctions with that building can become cooler. For example, one particular thermal modelling study by Peat, (2013) of a terraced dwelling undergoing improvements (including internal wall insulation (IWI)) identified a risk of condensation at the corner between the party wall and the external wall in all the dwellings before renovations. After one dwelling within the terrace was renovated, the risk was increased for the adjacent un-renovated dwellings. Where there is some cause for concern, modelling may help to 
indicate the need for other investigations, such as long-term monitoring of moisture content within fabric elements.

\section{4: Services Testing}

Although services are often regarded as a separate issue from fabric thermal performance, the move towards more air-tight buildings increases the importance of systems such as MVHR in maintaining the internal conditions required in a well-performing building.

In a number of cases it has been observed by the authors that MVHR systems were not delivering the required flow rates to the individual rooms and failed to comply with the ventilation requirements of Part F of the Building Regulations (2010). This suggests that the units had not been commissioned correctly. In fact, a recent study undertaken by BSRIA on the airflow performance of ventilation systems (Gilbert, 2013) found that $95 \%$ of systems failed to meet the requirements contained within the Building Regulations.

Other common issues observed include: poor system design (both of the unit and the supply and extract ductwork), inappropriate installation of units in dwellings with an air permeability in excess of $3 \mathrm{~m}^{3} /\left(\mathrm{h} . \mathrm{m}^{2}\right)$ at 50Pa, poor installation, inappropriate siting of the unit and the ductwork, inappropriate use of air supply and extract valves and lack of filter access.

\section{5: Other Investigations}

The examples given above represent only a small proportion of all the tests or investigations which might be undertaken in order to understand why a particular building is not performing as expected.

One of the most important techniques is often simple observation. In ideal cases where it is possible to observe the construction process, many potential problem areas may be identified, from on-site substitution of materials, products or design details to sequencing and process control issues, incorrect commissioning of services or lack of understanding of the principles leading to high thermal performance.

A good example may be found in the technical report on the Elm Tree Mews Field Trial (Wingfield et al., 2011a), where construction observations indicated a much greater timber fraction in the timber frame than was claimed by the original design. Subsequent heat flux measurements confirmed that the wall U-values were in fact around $66 \%$ higher than the design expectation.

Of course detailed observation of the construction or refurbishment process may not always be possible. However, even in a completed building, observation can often suggest a need for further testing, and is another example of the advantages of testing being undertaken by experienced researchers. A very simple example is observation of the failure of mastic seals due to accelerated drying out during a coheating test, causing deterioration in the airtightness of the dwelling, as shown in Figure 6 below. 


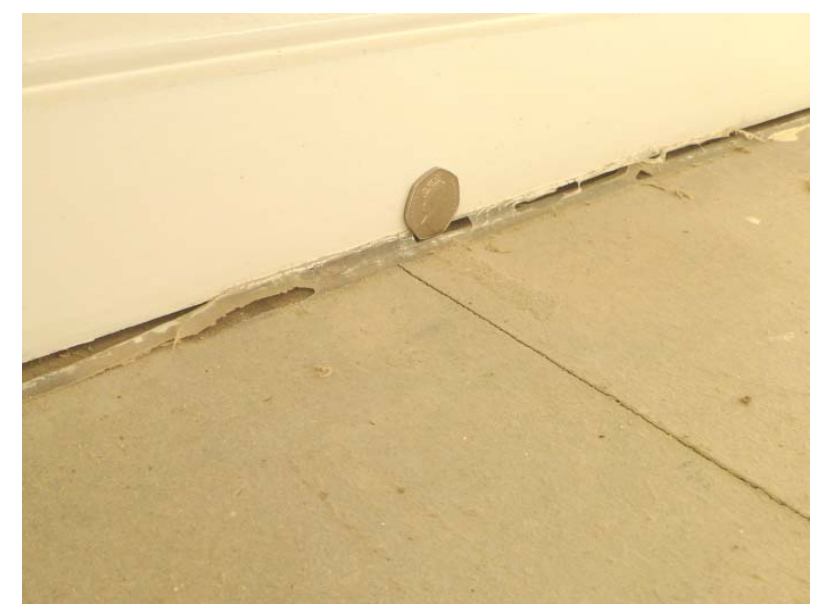

Figure 6: Failure of mastic seals due to accelerated drying during test.

Under these circumstances, increased air leakage through shrinkage cracks is expected, especially where the airtight barrier relies on secondary sealing to maintain its integrity, and this can have a significant effect on the overall measured heat loss of the property. Although this is not always preventable, the employment of pulse and decay $\mathrm{CO}_{2}$ measurements throughout the testing phase allows identification of any step changes in ventilation rate, which can subsequently be accounted for in the heat loss calculations.

\section{6: Additional Costs and Requirements.}

It has already been stated that the basic coheating test (measurement of heat loss coefficient) requires an investment of time and expertise, and is also relatively costly in terms of equipment required. Clearly additional investigations such as those discussed in sections $2.1-2.5$ also require expertise, especially in terms of exercising judgement about when and how to deploy them. The additional equipment required ranges from relatively cheap (e.g. smoke generators, surface temperature probes) to relatively costly (e.g. heat flux sensors, thermal imaging cameras). A reasonably good understanding of some buildings may be gained by the use of only a few investigative techniques, while others may require a different or wider set in order to fully explain observed behaviour. There is, at present, no simple way of pre-determining exactly which techniques will be most useful in different building types, though researchers may be guided by experience and observation in many individual cases.

\section{Adding Meaning to the Coheating Test Analysis}

If the coheating test period is used as an opportunity for acquiring detailed understanding of the building as described in section 2 , then the research team undertaking the test is not only able to ascertain the difference between measured and expected HLC (the "performance gap") but, more importantly is able to understand the specific causes of the difference, and even in some cases quantify the contributions of the main causes. 
This approach is sometimes called "closing the loop" and arguably should ideally be the ultimate aim of the investigative process. Again, the Elm Tree Mews Field Trial (Wingfield et al., 2011a) provides a good example (Figure 7). Here, the measured heat loss coefficient was effectively fully explained by differences in U-values of building elements (compared with design values) and differences in thermal bridging. These differences were quantified (or realistically estimated) from evidence collected on-site, and the close match between the effects of these investigations and the observed discrepancy in HLC supports the reliability and quality of the coheating test in this instance.

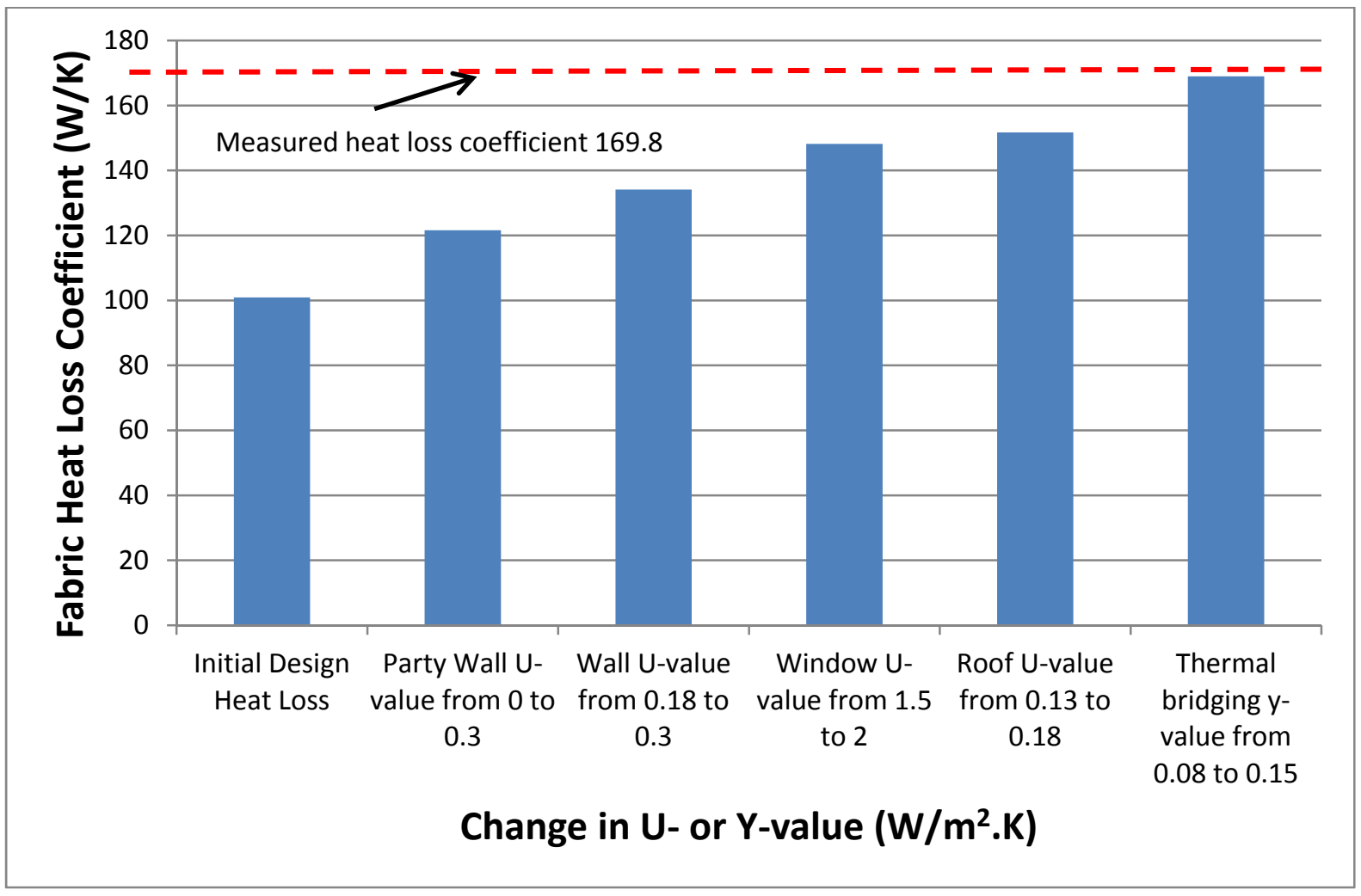

Figure 7: Taken from Elm Tree Mews Field Trial - Evaluation and Monitoring of Dwellings Performance - Final Technical report (Wingfield et al., 2011a) Fig. 108, p92.

Table 1 below summarises some of the more common sources of discrepancy, together with the types of tests which may identify and/or quantify the problem. Of course, characterisation of buildings is by its very nature an investigative process, and a simple 'tick-box' type approach is unlikely to be sufficient to result in deep understanding. The table is by no means exhaustive, and a range of other testing techniques may be appropriate in individual circumstances. 


\begin{tabular}{|l|l|l|}
\hline Source of Discrepancy & Type of Investigation & Understanding Gained \\
\hline $\begin{array}{l}\text { Plane element U-values } \\
\text { greater than expected }\end{array}$ & $\begin{array}{l}\text { Heat Flux measurements, } \\
\text { moisture measurements. }\end{array}$ & $\begin{array}{l}\text { Quantitative estimate of in } \\
\text { situ U-values, moisture } \\
\text { content of materials }\end{array}$ \\
\hline Air-tightness* & $\begin{array}{l}\text { Thermography, smoke } \\
\text { testing, pressurisation tests }\end{array}$ & $\begin{array}{l}\text { Main leakage points } \\
\text { identified. Thermography can } \\
\text { also identify leakage paths. }\end{array}$ \\
\hline Thermal Bypasses & $\begin{array}{l}\text { Heat flux measurements, } \\
\text { thermography, surface/cavity } \\
\text { temperature, cavity air flow, } \\
\text { etc. }\end{array}$ & $\begin{array}{l}\text { Existence of thermal bypasses } \\
\text { not accounted for in design } \\
\text { performance. Remedial work } \\
\text { and re-testing may allow for a } \\
\text { degree of quantification. }\end{array}$ \\
\hline Thermal bridging & $\begin{array}{l}\text { Modelling based on observed } \\
\text { details, thermography, } \\
\text { surface temperature } \\
\text { measurements. }\end{array}$ & $\begin{array}{l}\text { Differences between as- } \\
\text { designed and as-built details, } \\
\text { appropriateness of bridging } \\
\text { assumptions. }\end{array}$ \\
\hline $\begin{array}{l}\text { Substitution of products or } \\
\text { processes other than } \\
\text { specified }\end{array}$ & $\begin{array}{l}\text { Observations, heat flux } \\
\text { measurements, } \\
\text { thermography. }\end{array}$ & $\begin{array}{l}\text { Differences between as- } \\
\text { designed and as-built } \\
\text { performance. }\end{array}$ \\
\hline
\end{tabular}

Table 1: Summary of common sources of discrepancy between as-designed and as-measured heat loss coefficients.

* It is usual practice to use the actual measured permeability in the calculation for the predicted heat loss coefficient, so high permeability does not in itself give rise to a greater discrepancy between predicted and measured heat loss coefficients. However, if air permeability expectations are not being met, then this is important for the actual energy performance of the dwelling, and a good understanding of the reasons why will enable remedial measures to be undertaken more successfully.

\section{Optimising the Value of Coheating Testing}

In research terms, the coheating test forms a vital part of an investigation leading to detailed understanding and characterisation of the individual building. However, for routine commercial quality control purposes it has significant drawbacks in terms of cost, required resources of time and expertise, and the limitations on the testing season. For this reason, it would clearly not be practicable to require even basic measurement of HLC for all new constructions.

Some researchers are trying to address this problem by attempting to develop shortened or simplified tests which will yield a HLC value within a reasonable accuracy, and which could be used on a routine basis, particularly for new-build dwellings (Palmer et al., 2011; Lundin et al., 2004; Mangematin et al., 2012). Another approach is to abandon the steady state assumptions altogether, and attempt to characterise the building from real dynamic data using sophisticated statistical techniques (Andersen et al., 2000; Bloem, 2010). Dynamic methods for both whole buildings and 
building components are the subject of the current IEA Annex 58 project (Reliable Building Energy Performance Characterisation Based on Full Scale Dynamic Measurements).

Both these approaches, if successful, are likely to have vital parts to play in understanding and monitoring the thermal performance of the building stock as a whole. Nevertheless, a role still remains for conventional coheating testing, not only to validate other steady-state methods, but perhaps even more importantly to form part of a suite of highly intensive investigations in circumstances where much greater in-depth understanding is required. This may be the case in, for example, prototyping of new designs or techniques, or further investigation of suspected generic problems.

\section{Conclusions}

The co-heating test is often regarded simply as a method of obtaining a whole-house heat loss figure. Without deeper understanding of the factors contributing to any discrepancy between this figure and the designed or expected heat-loss, the test is of limited value and may justifiably be criticised as expensive and time-consuming.

However, the coheating test provides an opportunity, basis and environment for a whole raft of detailed investigations which may be undertaken with a view to gaining a much fuller understanding of the building's thermal performance. The coheating test, in the context of the additional investigations can then not only identify any performance gap, but also attempt to explain its origins and magnitude.

Investigations based around the co-heating test platform performed by Leeds Metropolitan University researchers over a period of many years have enabled a wide range of important issues to be identified and understood, including process and installation issues, as-designed and as-built discrepancies, differences between nominal and in situ U-values, and previously poorly understood heat loss mechanisms such as the party-wall bypass.

Clearly the type of in-depth testing discussed here is not likely to be adopted by the construction industry as a routine procedure for large-scale testing. Nevertheless, it has an important role to play in prototyping of designs, validation of alternative methodologies and detailed investigations of complex problems and performance shortfalls. 


\section{$\underline{\text { References }}$}

Andersen, K. K., Madsen, H. and Hansen, L. H. (2000). "Modelling the heat dynamics of a building using stochastic differential equations." Energy and Buildings, 31 (1) pp13-24.

ATTMA (2010) "Technical Standard 1. Measuring Air Permeability of Building Envelopes." Air Tightness Testing and Measurement Association. Issue 1. Available at: $\langle\underline{w w w . a t t m a . o r g}\rangle$. (Accessed September 2013)

Bloem, J. J. (2010). "Dynamic Methods for Building Performance Assessment." $5^{\text {th }}$ European Conference on Energy Performance \& Indoor Climate in Buildings, PALENC, Rhodes, 29th September$1^{\text {st }}$ October 2010. Available at: $<w w w . j u s t-p m . e u / d y n a s t e e / p u b l i c a t i o n s / p a p e r s>$ (Accessed September 2013)

Gilbert, A. (2013) "Practical Experience of Common Ventilation Problems." [Internet] Bracknell, UK, BSRIA. Available from: <www.goodhomes.org.uk/events/101>. (Accessed July 2013)

ISO (1994) ISO 9869:1994 "Thermal Insulation - building elements - in situ measurement of thermal resistance and thermal transmittance." Geneva, Switzerland. ISO.

Johnston, D., Miles-Shenton, D., Farmer, D. and Wingfield, J. (2013). "Whole House Heat Loss Test Method (Coheating)." Leeds Metropolitan University, June 2013. Available at:

$<$ www.leedsmet.ac.uk/as/cebe/projects.htm>. (Accessed September 2013)

Lowe, R.J., Wingfield, J., Bell, M. and Bell, J.M. (2007). "Evidence for significant heat losses through party wall cavities in load-bearing masonry construction." Building Services Engineering Research \& Technology. 28 (2) pp161-181.

Lundin, M., Andersson, S. and Östin, R. (2004) "Development and Validation of a method aimed at Estimating Building Performance Parameters." Energy and Buildings 36 (9) pp905-914.

Mangematin, E., Pandraud, G. and Roux, D. (2012) "Quick Measurements of Energy Efficiency of Buildings." C. R. Physique 13, pp383-390

Palmer, J., Pane, G., Bell, M. and Wingfield, J. (2011) “Comparing primary and secondary terms analysis and renormalisation (PStar) test and co-heating test results. A Report to the Department for Communities and Local Government." HMSO, London. ISBN 978140982902 7. Available at: $<$ www.leedsmet.ac.uk/as/cebe/projects/htm>. (Accessed September 2013).

Peat, M. (2013) "Building Fabric Performance Modelling: Thermal Bridging Report" [Unpublished report prepared for Leeds Environmental Design Associates]. Leeds Metropolitan University.

Sonderegger, R. C. Condon, P. E. and Modera, M. P. (1979) "In-situ measurements of residential energy performance using electric co-heating." ASHRAE Transactions, Vol. 86 (I), 1980. LBL-10117.

Sonderegger, R. C. and Modera, M. P. (1979) "Electric co-heating: A method for evaluating seasonal heating efficiencies and heat loss rates in dwellings." Proceedings of the Second International CIB Symposium, Energy Conservation in the Built Environment, Copenhagen:1979. LBL-8949. 
Stafford, A., Bell, M. and Gorse, C. (2012). "Building Confidence - a working paper." Centre for Low Carbon Futures report No. 008 (2012). Available at:

$<$ www.lowcarbonfutures.org.uk/reports/research-reports $>$. (Accessed September 2013)

UK Building Regulations (2010). Crown Copyright. Approved Document F - Ventilation. NBS: London 2010. Available at <www.planningportal.gov.uk> (Accessed September 2013)

Wingfield J. (2010) "Technical Note: Measurement of Heat Loss via Thermal Bypasses in Separating Party Wall Cavities." Leeds Metropolitan University, August 2010. Available at:

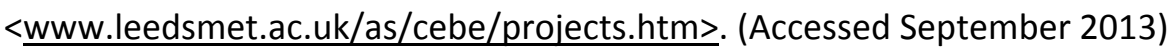

Wingfield, J., Bell, M., Miles-Shenton, D., South, T. and Lowe, R. (2011a) "Evaluating the impact of an enhanced energy performance standard on load-bearing masonry domestic construction.

Understanding the gap between designed and real performance: lessons from Stamford Brook." DCLG (2011). Available at: <www.leedsmet.ac.uk/as/cebe/projects.htm>. (Accessed September 2013)

Wingfield J., Bell, M., Miles-Shenton, D. and Seavers, J. (2011b). “Elm Tree Mews Field Trial Evaluation and Monitoring of Dwellings Performance. Final Technical Report." Leeds Metropolitan University, January 2011. Available at: <www.leedsmet.ac.uk/as/cebe/projects.htm $>$. (Accessed September 2013)

Zero Carbon Hub (2010). "Carbon Compliance for Tomorrow's New Homes: A Review of the Modelling Tool and Assumptions. Topic 4: Closing the Gap between Designed and Built Performance." Zero Carbon Hub, August 2010. Available at: <www.zerocarbonhub.org $>$. (Accessed September 2013) 